\title{
Costs and effectiveness of the supervision, performance assessment and recognition (SPARS) strategy for medicines management in Uganda
}

\author{
Brendan Kwesiga ${ }^{1}$, Anita Katharina Wagner ${ }^{2}$, Morries Seru ${ }^{3}$, Dennis Ross-Degnan ${ }^{2}$ and Birna Trap ${ }^{1^{*}}$ (D)
}

\section{Background}

Essential medicines and health supplies (EMHS) are fundamental to providing quality health care that is critical for saving lives. Ensuring that medicines of good quality are available, accessible, affordable, and appropriately used is a key objective of the Uganda National Medicines Policy [1]. Central to achieving this objective are good medicines management practices at all health facilities. Despite Uganda's long-standing commitment to its medicines policy, the pharmaceutical supply chain has faced many well-documented constraints [2-5].

\section{Uganda's health system}

Uganda's estimated population was 38.8 million people as of 2018. The population size is growing at an average annual rate of $3 \%$, which is one of the highest in the world [6]. Communicable diseases remain the leading cause of years of life lost and result in $48 \%$ of the mortality in Uganda; in addition, non-communicable diseases are becoming increasingly important as a cause of morbidity and mortality [7].

In 2013, Uganda had 116 administrative districts with 6404 health facilities. Of these $48 \%$ were governmentowned, $15 \%$ were private not-for-profit, and the rest (37\%) private for-profit [8]. The public sector consisted of government and private not-for-profit facilities and included two national referral hospitals, 16 regional referral hospitals, 117 general hospitals, 196 health centers (HC) level IV, 1291 HCIII and 2354 HCII facilities. EMHS for government facilities are supplied through the government-owned National Medical Stores [7]. The private not-for-profit facilities are supplied through the

\footnotetext{
* Correspondence: birna.trap@gmail.com

${ }^{1}$ USAID/Uganda Health Supply Chain Program, Management Sciences for Health, Plot 15, Princess Anne Drive, Bugolobi, P.O. Box 71419, Kampala, Uganda

Full list of author information is available at the end of the article
}

Joint Medical Stores. Medicines are supplied free of charge to patients in government facilities.

In fiscal year 2015/16 the total government budget allocated to EMHS in government facilities was US\$94 million with per capita government sector EMHS expenditures of only US $\$ 0.80$ (excluding antiretroviral treatment, tuberculosis, and malaria medicines) [9]. When we consider the external donor budget for antiretroviral treatment, tuberculosis, malaria medicines and some essential medicines for the same year $(2015 / 16)$, per capita EMHS expenditures were US\$1.90 [10]. In view of severe governmental resource constraints and substantial donor investments (close to $80 \%$ of total medicines expenditures in 2015/116) [9], strengthening medicines management is crucial for maximizing scarce resources and limiting waste.

Medicines management processes include quantification, procuring, storage, stock management, prescribing, dispensing, ordering and reporting. These processes are complex and often interlinked and their implementation must be well managed to achieve optimal outcomes. Successful implementation of good medicines management practices requires adequate regulatory, financial, and human resources including facility staff with the appropriate skill set and relevant information [11].

In an effort to improve medicines management capacity at health facilities, Uganda developed and implemented a multi-pronged, evidence-based supervision, performance assessment, and recognition strategy (SPARS) [12]. SPARS combine supervision with indicator-based performance assessment to identify problems, track improvements and includes facility recognition schemes. Performance is assessed in five domains (ordering/reporting, stock and storage management, prescribing, and dispensing) using 25 indicators. Medicines management supervisors (MMS) visit facilities to assess staff performance using pre-defined 
data collection forms. Based on the assessment the MMS identify areas in need of improvement, and they support facility staff in implementing change. MMS then enter SPARS scores into the online pharmaceutical information portal (PIP).

The information generated through SPARS guides strategic decisions to improve access, ensure availability, and encourage appropriate use of EMHS [13]. SPARS has improved performance in all medicines management domains across all levels of care [14].

Whereas the benefits of SPARS in improving medicines management are well documented [14], we wanted to estimate the costs and cost effectiveness of SPARS implementation in public (government and private notfor-profit) health facilities in Uganda. This information is critical for further SPARS scale up in Uganda and for SPARS implementation in countries with similar contexts that want to consider rolling out SPARS as a national strategy.

\section{Methods \\ SPARS intervention}

SPARS has been implemented by Uganda's Ministry of Health since 2010 with support from the US Agency for International Development. SPARS is implemented by district-level health care staff who are trained as MMS to provide on-the-job supervision and training of health workers. Components of the SPARS program are summarized below and detailed elsewhere [12].

\section{Components of the SPARS program MMS selection}

The district health officers (DHOs) select three to five MMS in their districts depending on the number of health sub-districts. One district-level MMS supervises hospitals and HCIV facilities, and one to four health sub-districtMMS supervise lower-level health facilities in the health sub-districts. MMS are health workers who are already employed within the district health system; MMS can be clinical officers, nurses, midwives, pharmacy staff, or storekeepers that implement SPARS along with other duties; the supervisory task is an added responsibility. The DHO monitors performance of MMS with oversight from regional pharmacists and the Ministry of Health's Pharmacy Department.

\section{Equipment provision}

To facilitate the performance assessment and ensure high-quality data, each MMS is provided with a computer (netbook) and a modem for electronic data submission. To enable MMS to travel to the facilities they supervise, they are provided with a motorcycle $(175 \mathrm{cc}, 4$ stroke) and appropriate riding gear including helmets and boots. The motorcycle is meant to be used exclusively by the MMS to ensure long life, although the MMS might use the motorbike for other work-related business.

\section{MMS capacity building}

To become qualified, MMS have to undergo several SPARS trainings that include a theoretical training, a practical field orientation, defensive motorbike training, computer training, and data use training. The theoretical training is a two-week examinable residential workshop. The workshop covers medicines management, problemsolving, communication, mentoring, assessing performance using SPARS indicators, and work planning and reporting. To ensure quality and sustainability, the training is implemented by faculty from Makerere University. Next comes a five-day in-service supervision of the MMS implemented by experienced MMS in the trainees' district or in nearby districts. MMS then take part in a three-day residential workshop on the use of computers and data entry and use. Each MMS finally receives a sixday residential course on defensive motorcycle riding, repairs, and licensing implemented by professional motorbike drivers and mechanics. The MMS are provided with supervision tools such as an EMHS manual, stock books, a supervisory book to record and track assessment findings and agreed tasks and laminated job aids. A white board displaying a spider graph that depicts and tracks each facility's SPARS implementation and performance is also provided.

\section{Number of visits}

In addition to supervising higher-level facilities, the district MMS also have the responsibility for mentoring and supporting the health sub-district MMS. District and health sub-district MMS are expected to make three and five supervisory visits per month, respectively, and each health facility should be supervised about five times within the first year of SPARS. After five visits, the facility staff should have built the skills required to ensure good medicines management, and subsequent supervisions are focused on maintaining these skills. After finishing the initial five visits to their assigned facilities, MMS can start taking on other tasks. These tasks include supervising pharmaceutical financial management or antiretroviral management, redistribution of supplies, and supporting medicines therapeutic committees. All tasks, that are relevant for strengthening medicines management beyond SPARS.

\section{MMS facilitation}

Following each supervisory visit, the MMS submits his or her SPARS report into the PIP, an online information system. The MMS is then eligible to receive a daily travel allowance and transport allowance enough to 
cover fuel, minor repairs, and oil changes. The payment is made using mobile money following each visit documented through the SPARS report submission.

\section{Repair and maintenance}

To ensure that motorcycles and computers remain functional to support SPARS implementation, routine repair and maintenance are critical. The DHO receives funds for annual motorcycle service and maintenance, insurance, repairs, and a set of new tires annually per motorbike. The funds for motorcycle maintenance and repair are linked to a minimum number of MMS supervision visits implemented and documented with reports.

\section{Communication, coordination, and collaboration}

To ensure coordination and collaboration among the DHOs, MMS, other Ministry of Health staff, and community partners in SPARS implementation, the Ministry of Health organizes quarterly implementing partner and district coordination meetings. The Ministry of Health also disseminates district, regional, and national SPARS performance reports to monitor the performance of MMS and to share lessons learned [13]. The DHO receives airtime and telephone-time to coordinate and oversee SPARS implementation in the district. The MMS also receive airtime and internet-time for communication and data submission.

\section{SPARS information use}

To facilitate evidence-based decision making for improving medicines management, all SPARS reports are collected centrally and stored in the PIP. To improve the use of SPARS data, all MMS and DHO have been trained in accessing and using the PIP and generating reports based on SPARS data.

\section{Recognition scheme}

Health facilities that meet performance goals receive items such as tea and sugar, mugs, pens, a wall clock, Tshirts, and calendars. During SPARS implementation, health facilities were also provided some items that the Ministry of Health should have provided, including thermometers, stock books, and shelves to store EMHS.

\section{Measurement of costs}

Through this study, we intended to answer two questions: (1) What does it cost per year to implement and operate SPARS as a national strategy? and (2) What were the SPARS-related costs for a health facility to attain an adequate SPARS score?

We answered the first question by calculating the costs to implement and run SPARS for three years per facility between 2011 and the end of 2014. The costs captured were those incurred to strengthen medicines management and are incremental to the costs of routinely supplying medicines in existing systems. Although during SPARS implementation, health facilities were provided with standard pharmacy equipment such as tools for medicines management (stock books, stock cards, borrow and lend records, expired medicines registers, EMHS list, EMHS manual, clinical guidelines, tablet counting trays, plastic dispensing bottles, measuring beakers, spatulas, dispensing envelopes, shelving units, and thermometers). We did not include the cost of these items in the SPARS cost estimate because they should be supplied as part of standard system operations. We chose a conservative approach by including the full cost of capital items (computers, motorbikes, service and maintenance) even though they might be used for other purposes beyond SPARS. We annualized all capital costs based on their expected useful life and applied a discount rate of $3 \%$ to obtain their annual depreciation value. We estimated the costs of data management by including the cost of the MMSs' computers, modems, air- time, and MMS training in data entry and use. We did not include the salaries for the DHO, regional pharmacists, and district staff working part time as MMS because these staff already have supervision and oversight as part of their job descriptions. However, SPARS has made supervisory visits more regular and effective. The cost of oversight and supervision of MMS by district, regional and central level staff have been included. Costs for program personnel ${ }^{1}$ and Pharmacy Department staff to design, coordinate, and implement SPARS have been excluded as it is part of existing duties and salaries.

We used information from the SPARS program staff, program reports, expenditure records, and invoices from 2011 through 2014 to identify activities and resource inputs used to implement SPARS. We used 2016 prices to value the resource inputs and estimate the costs because those were readily and completely available. Thus, no inflation adjustment was done. We collected data in both Uganda shillings (UGX) and United States (US) dollars based on the currency used to procure inputs and implement activities. In the analysis and presentation of results, cost data is presented in 2016 US\$ using an average exchange rate between 2011 and 2014 of UGX 3500 to US\$1.

To answer the second question, we calculated the SPARS effectiveness as the cost for a health facility to reach adequate SPARS score.

\section{Measurement of intervention effectiveness}

Measurement of SPARS effectiveness has been described before $[12,14]$. For this study, we used data from the PIP database and selected 1460 facilities that started

\footnotetext{
${ }^{1}$ The USAID-funded Securing Ugandans Right to Essential Medicines program led SPARS implementation with the Ministry of Health.
} 
SPARS implementation in 2011 or 2012 and followed each facility for three years to assess SPARS effectiveness. When a health facility reached $75 \%$ of the maximum SPARS score-18.75 of 25 points-during the three observation years, its medicines management practices were deemed effective. In general, a facility that achieves a 75\% SPARS score is performing adequately in the SPARS domains of dispensing quality, prescribing quality, stock management, storage management, and ordering and reporting.

\section{Measures of SPARS cost-effectiveness}

As the purpose of SPARS is to improve medicines management at health facilities, the cost-effectiveness analysis aimed to determine the costs for a health facility to attain an adequate SPARS score. To assess SPARS cost effectiveness, we estimated the cost per health facility to achieve a SPARS score $\geq 18.75$ over the three-year observation period per facility. We divided the total incremental cost of SPARS implementation over the follow-up period (three years for each of 1460 facilities) by the number of facilities that attained the desirable SPARS score over the same period (899). We excluded the five facilities having an adequate score at baseline. Total costs were incurred in four calendar years $(2011,2012$, 2013, and 2014) because facilities were enrolled in 2011 and 2012 and then followed for three observation years within four calendar years, and then divided by three to determine an annual cost.

\section{Sensitivity analyses}

To assess whether the estimated incremental costeffectiveness ratio (ICER) is robust to changes in either cost or effectiveness calculations, we carried out sensitivity analyses. With regards to costs, we varied potential cost drivers by including costs of the standard pharmacy equipment, costing different approaches to MMS training (base case is using a training institution versus inhouse training), and assuming there is already capacity among MMS in computer use and motorcycle riding.

We assessed the robustness of the ICER to change in effectiveness based on $\mathrm{a} \pm 10 \%$ change in the number of facilities attaining an adequate SPARS score. We also estimated the best-case scenario (based on the lowest cost and highest effectiveness) and worst-case scenario (based on the highest cost and lowest effectiveness) within the plausible ranges considered for the sensitivity analysis.

\section{Results}

This section presents the costs, effectiveness, and the cost effectiveness following SPARS implementation between 2011 and 2014. To link cost and effectiveness, we estimate the incremental cost effectiveness ratio. We also present results of the sensitivity analysis.

\section{Costs}

Table 1 shows the annual costs of implementing SPARS in 1460 facilities between 2011 and 2014. In total, the 1460 facilities received 7616 supervisory visits (i.e., about five visits per facility) over the three-year per facility follow-up period. The 264 MMS who made the supervisory visits were fully trained and equipped.

The total cost of implementing SPARS in 1460 facilities over three years was US $\$ 1,105,190$, while the annual cost was US\$368,397. The capital/establishment costs accounted for $53 \%$ and operating costs for $47 \%$ (Table 1).

As noted, SPARS implementation relies on using MMS who are government employees within their districts and undertake medicines management supervision as an additional responsibility. Therefore, labor costs are covered within their existing government salaries.

\section{Effectiveness}

Table 2 shows the effectiveness of SPARS in the 1460 health facilities that received supervisory visits for three years between 2011 and 2014. At baseline (visit 1) the median SPARS score across all health facilities was 10.3. Over $60 \%(904 / 1460)$ of the facilities attained and maintained an adequate SPARS score of $\geq 18.75$ during that time; five facilities had already reached the target score at baseline. Therefore, we assessed the incremental effectiveness as $61.6 \%$ based on 899 facilities that increased their inadequate scores at baseline over the course of the three years of SPARS supervision.

The 1460 facilities received 7616 supervisory visits, with a median of six visits per facility and a range of 1-12 visits over the three-year period. The 904 facilities with an adequate score at their last visit received 4227 visits with a median of five visits and a range of $1-12$ visits.

\section{Cost effectiveness of SPARS}

Table 3 presents the total cost associated with implementing SPARS for medicines management within an existing health system and the additional effectiveness due to implementing SPARS. The results show that the incremental cost for every additional facility attaining the desirable SPARS score is equal to US $\$ 1229$.

\section{Sensitivity analysis}

We assessed how the estimated ICER varied with changes to parameters that influence the cost of SPARS. Figure 1 shows that the biggest cost driver is the investment in equipping the MMS. The most cost-effective scenario (i.e., variation that produces the lowest ICER) is when we assume that the MMS do not have to be equipped. The least cost-effective approach (highest ICER) is when health facilities have to be provided with all standard equipment for properly supplying medicines, including shelving. 
Table 1 Annualised economic cost of establishing and implementing SPARS

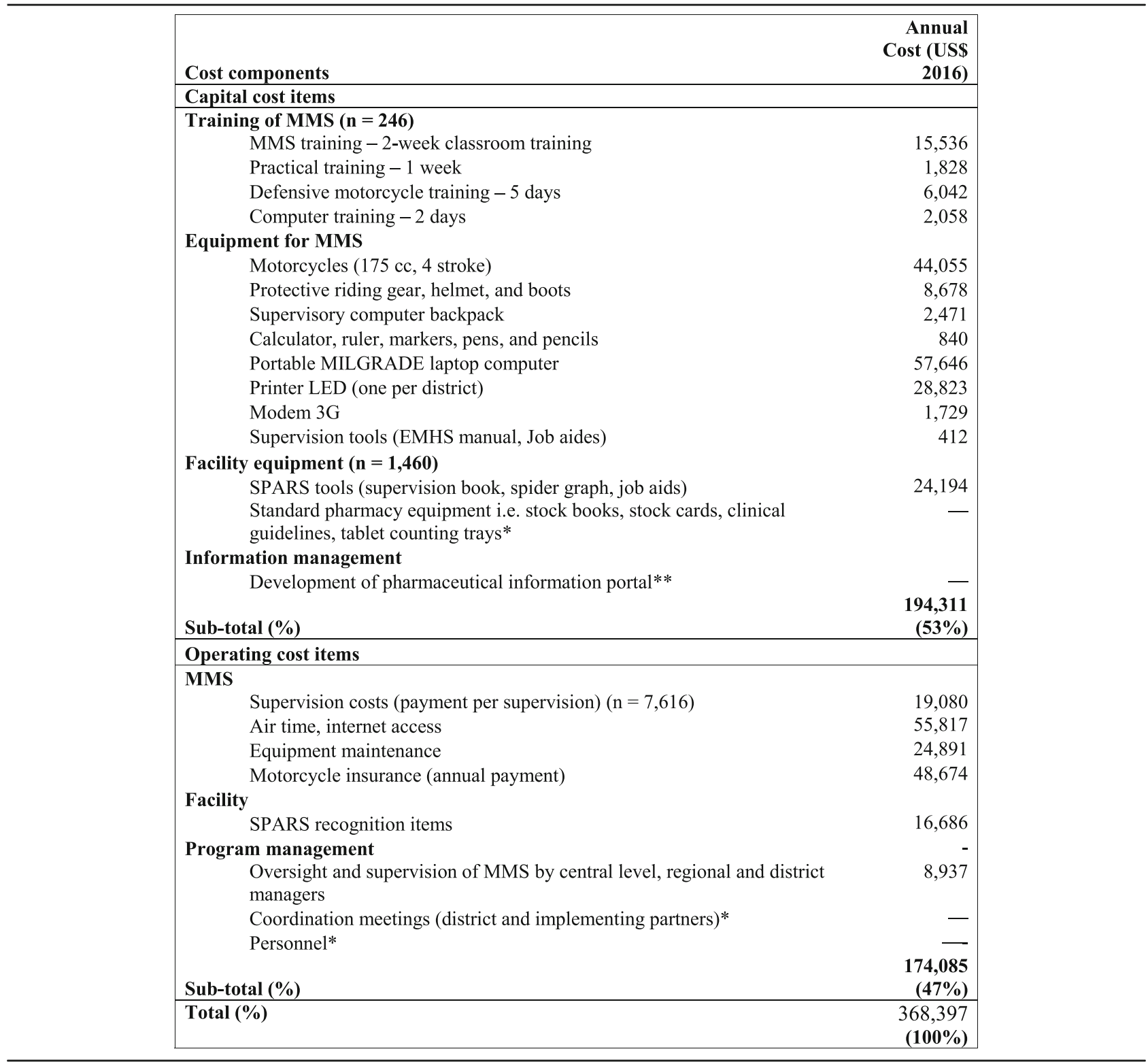

${ }^{*}$ Costs covered within existing duties, salaries or by government ordinary expenses

${ }^{* *}$ Although funded by the donor, PIP development cost was not included in the calculations as the SPARS does not depend on PIP

Table 2 Effectiveness of SPARS following three years of SPARS implementation

\begin{tabular}{|lrr|}
\hline Facility score & Baseline (\%) & Last visit* (\%) \\
\hline Facilities with score $<18.75$ & $1455(99.7 \%)$ & $556(38.1 \%)$ \\
Facilities with score $\geq 18.75$ & $5(0.3 \%)$ & $904(61.9 \%)$ \\
Total SPARS facilities & $1,460(100 \%)$ & $1,460(100 \%)$ \\
\hline Incremental effectiveness & & $\mathbf{8 9 9}(\mathbf{6 1 . 6 \% )}$ \\
\hline
\end{tabular}

*Last visit within a three-year follow-up period per facility 
Table 3 SPARS cost-effectiveness ratios

\begin{tabular}{|lr|}
\hline Total SPARS cost over 3 years & US\$1,105,190 \\
\hline Total number of facilities implementing SPARS & 1,460 \\
Total number of visits & 7,633 \\
Total number of facilities attaining a score $\geq 18.75$ & 899 \\
\hline Cost per facility implementing SPARS & US\$757 \\
Cost per supervisory visit & US\$145 \\
Cost per facility achieving SPARS score $\geq 18.75$ & US\$1,229 \\
\hline
\end{tabular}

The combined variation of both cost and effectiveness within a defined range (number of facilities attaining satisfactory score +/-10\%) shows that the SPARS ICER ranges from 2016 US\$1000 (best case) to US\$1494 (worst case) (Table 4).

\section{Discussion}

The study assessed the cost and cost effectiveness of implementing SPARS, which is a multi-pronged intervention to improve medicines management practices at facility level. Evidence shows that SPARS is an effective intervention to improve performance in key medicines management domains [14]. However, to implement a system-strengthening intervention, knowing the cost and potential return on the investment is important. In this study, we not only show what it costs to implement SPARS, but also the costs for a health facility to reach an adequate SPARS performance. To our knowledge, this is the first study to estimate costs and cost effectiveness of a comprehensive supportive supervision strategy to improve medicines management in a health system. A previous study that looked at the cost-effectiveness analysis of a supportive supervision intervention - strengthening immunization service delivery in India found, that it would cost US\$3091 to obtain a $1 \%$ increase in health facility immunization performance scores [15].

How can we judge whether investing in SPARS to improve facility medicines management is worthwhile? Leech and colleagues have urged that the decision on whether an intervention (such as SPARS) is cost effective should reflect the health system context, challenges, and priorities [16]. Availability of medicines within a health system is the foundation for improving population health outcomes. When medicines are not well managed, products expire or spoil, medicines shortages occur, and patients receive no medicines, poor quality medicines, or inappropriate medicines [17]. It has also been noted that improving supply chain management by increasing efficiency and effectiveness is critical in reducing the global burden of disease, especially in resource-

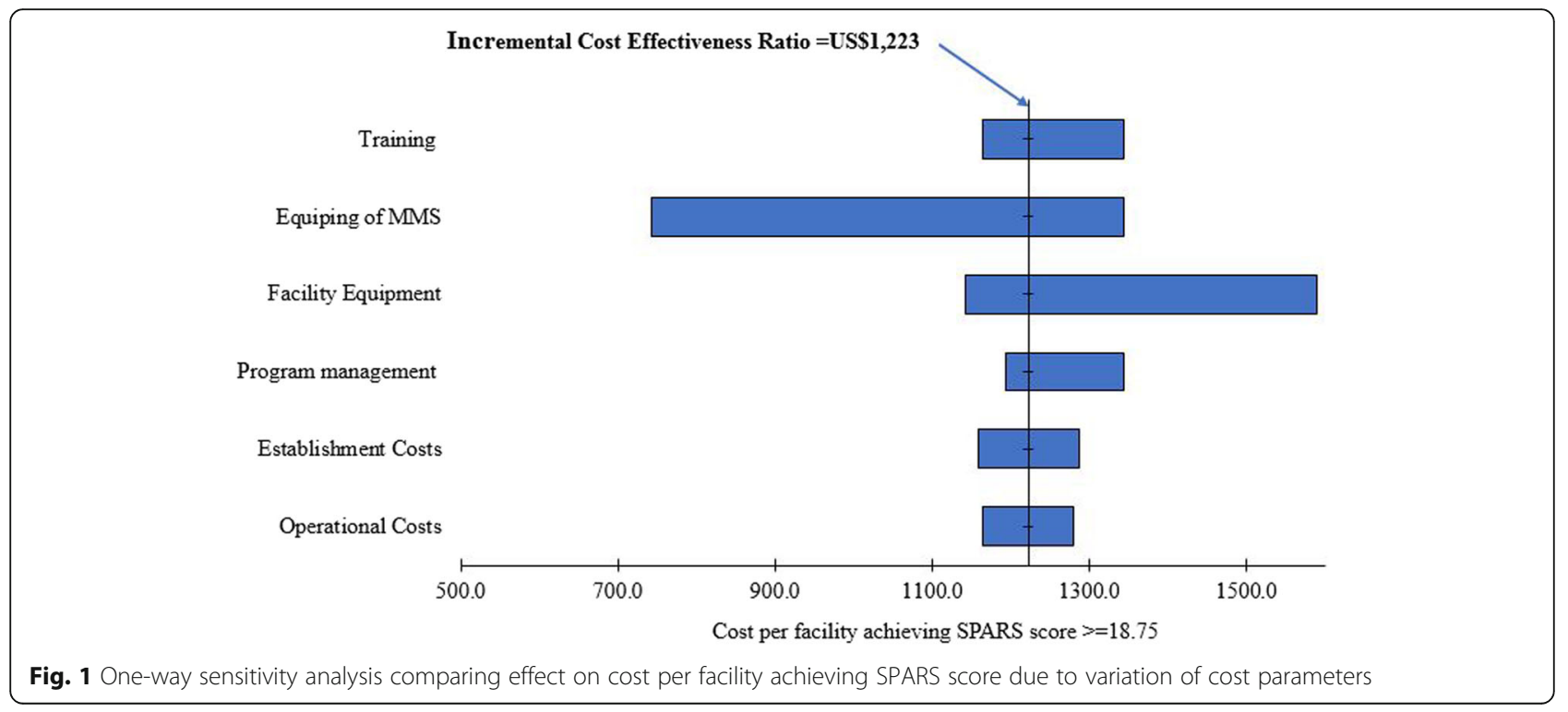


Table 4 Sensitivity analysis scenarios

\begin{tabular}{|lrrr|}
\hline & Best case & \multicolumn{1}{c|}{ Base case } & Worst case \\
\hline Total SPARS cost & US $\$ 994,671$ & US $\$ 1,105,190$ & US $\$ 1,215,709$ \\
Total number of facilities with score $\geq 18.75$ & 989 & 899 & 809 \\
Cost per facility achieving SPARS score & US $\$ 1,006$ & US $\$ 1,229$ & US\$1,503 \\
$\geq 18.75$ (US\$) & & & \\
\hline
\end{tabular}

limited settings [18]. In fiscal year 2015/16, the Government of Uganda allocated $18 \%$ of the total health budget to medicines and medical supplies (which is the second largest line item after personnel/human resources expenses). Although this proportion is significant, the actual amount allocated in real terms is sub optimal. The existing per capita allocation for medicines of \$2 result in sub-optimal availability of medicines even with significant donor funding [9]. Given enormously limited resources available for medicines procurement, it is critically important to optimize these resources and minimize waste. SPARS provide the system foundations to manage scarce medicines resources well.

While this study does not directly link better medicines management with savings from reduced waste and better health outcomes, others have shown that supply chain strengthening can reduce stock outs and increase medicines availability [19]. Seidman and Atun recommend that policy makers "examine the root causes of inefficiencies in pharmaceutical supply chain and procurement processes to determine how best to improve health systems performance". In 2010, the Ugandan Ministry of Health conducted a policy options analysis [20], which was informed by a baseline assessment of root causes of inefficiencies that gave rise to the design and implementation of SPARS [21]. Having previously shown SPARS effectiveness [14], our paper details the costs of SPARS to achieve the desired effect.

If investing in SPARS is considered worthwhile to facilitate effective and efficient use of the Ugandan government's annual EMHS budget, can the Ugandan government afford it? In 2015/16 the government spent US $\$ 94$ million on EMHS [10], while donors spent over US\$200 million [9]-mainly on medicines for HIV, tuberculosis, and malaria. Based on our estimates from this study, implementing and operating SPARS costs about US\$370,000 annually for 1460 facilities, which would extrapolate to approximately US\$760,000 for about 3000 government sector facilities or about $0.3 \%$ of the total government- and donor-funded EMHS budget.

Donors and development partners may want to contribute to SPARS implementation because SPARS provides facility staff the basic medicines management skills. These skills are critical for managing all medicines, including antiretrovirals and other high-cost medicines, for strengthening pharmaceutical information systems, and for managing pharmaceutical finances to assure efficient use of donor resources. In Uganda, we also found that MMS contributed to health system objectives beyond SPARS, such as shifting from a kit- to an orderbased EMHS distribution system, applying cost recovery mechanisms, and facilitating the introduction of new clinical guidelines. Donor and country investment in pharmaceutical supply chain systems seems a prerequisite for effective and efficient use of development funds and will form a foundation for stronger health systems, including the ability to address emerging challenges, such as non-communicable diseases [11].

\section{Limitations}

We only observed facilities for three years, which restricts our knowledge of longer-term costs and effectiveness. Further, the investment required for implementing SPARS for the first time will depend on how rudimentary the basic structures and processes of a country's health and pharmaceutical systems are; some may need to make investments that Uganda already had in place, such as human resources and a health facility supervisory infrastructure. In addition, the potential effectiveness of SPARS will depend on facility performance at the initial visit [14]; a country could decide to implement SPARS only in poorly performing facilities.

\section{Conclusion}

While several studies document the effects of interventions based on supportive supervision, documentation of the costs and cost-effectiveness of such interventions are limited. We document the costs and cost effectiveness of a strategy that has been shown to improve medicines management performance in Uganda. Without sound and transparent EMHS management that enables affordable access to medicines, low-income countries such as Uganda will not be able to achieve the goals of universal health coverage. Putting in place systems to manage medicines efficiently will optimize the use of funds and lead to the sustainable financing that is a critical component of a health system that provides coverage to all. 


\section{Abbreviations}

DHO: District health officer; EMHS: Essential medicines and health supplies; HC: Health centers; ICER: Incremental cost effectiveness ratio; MMS: Medicines management supervisors; PIP: Pharmaceutical Information Portal; SPARS: Supervision Performance Assessment and Recognition Strategy; UGX: Uganda shillings; US: United States; USAID: United States Agency for International Development

\section{Acknowledgements}

We thank Richard Musoke and Emmanuel Egwenyu who provided statistical analysis support. We also acknowledge the comments and editorial support provided by Martha Embrey.

\section{Authors contributions}

BK, AKW, DRD, and BT conceived of, designed, and oversaw the study. They developed the study methods, took part in the implementation, and drafted and edited the manuscript. BK, AKW, BT, MS, and DRD contributed to data analysis, interpretation, writing of the manuscript, and quality assurance. All the authors read and approved the final version.

\section{Funding}

This study was funded by the United States Agency for International Development (USAID). USAID did not have any role in the study design, data analysis, or writing of this paper or in the decision to submit the paper for publication.

\section{Availability of data and materials}

Data analyses, and other materials can be obtained upon request from the corresponding author

\section{Ethics approval}

This study assesses cost effectiveness of a national capacity-building strategy and reports aggregated facility medicines management data collected by medicines management supervisors in their roles as district employees and supervisors. The study did not involve or use human subjects or identifiable personal data, human tissue, or animals, and thus did not require ethical approval or a waiver. The study was implemented with the permission of and in collaboration with the Ministry of Health, and all information is kept anonymous. All authors of the manuscript have read and agreed to its content and are accountable for all aspects of the accuracy and integrity of the manuscript in accordance with ICMJE criteria.

\section{Consent for publication}

The article is original, has not been published in a journal, and is not currently under consideration by another journal. The Uganda Ministry of Health has provided consent for publication.

\section{Competing interests}

The authors declare that they have no financial or none-financial competing interests. This study was funded by the United States Agency for International Development (USAID). USAID did not have any role in the study design, data analysis, or writing of this paper or in the decision to submit the paper for publication.

\section{Author details}

'USAID/Uganda Health Supply Chain Program, Management Sciences for Health, Plot 15, Princess Anne Drive, Bugolobi, P.O. Box 71419, Kampala, Uganda. ${ }^{2}$ Harvard Medical School and Harvard Pilgrim Health Care Institute, 401 Park Drive Suite 401, Boston, MA 02215, USA. 'Ministry of Health, Pharmacy, Division, Lourdel Road, Wandegeya, Kampala, Uganda.

Received: 5 July 2019 Accepted: 17 October 2019

Published online: 03 December 2019

\section{References}

1. Ministry of Health. National Medicines Policy of Uganda. 2015;(july):38. [Accessed April 28 2019] http://apps.who.int/medicinedocs/en/m/abstract/ Js22314en/

2. Windisch R, Waiswa P, Neuhann F, Scheibe F, de Savigny D. Scaling up antiretroviral therapy in Uganda: using supply chain management to appraise health systems strengthening. Glob Health. 2011;7(1):25. https://doi. org/10.1186/1744-8603-7-25

3. Ministry of Health Uganda. Uganda Pharmaceutical Sector Report 2010:; 2010. [Accessed April 28 2019] http://library.health.go.ug/publications/ medical-products-technologies/pharmaceuticals-and-drugs/ugandapharmaceutical-sector.

4. Ministry of Health Uganda. Uganda Pharmaceutical Sector Report 2011.; 2011. [Accessed April 28 2019] http://health.go.ug/content/ugandapharmaceutical-sector-report-2011.

5. Trap B, Kikule K, Vialle-Valentin C, et al. First regulatory inspections measuring adherence to good pharmacy practices in the public sector in Uganda : a cross-sectional comparison of performance between supervised and unsupervised facilities. J Pharm Policy Pract. 2016;9(18):1-10. https://doi. org/10.1186/s40545-016-0068-4.

6. UBOS. Uganda National Household Survey (UNHS) 2016/17. 2017; (September):272. [Accessed April 28 2019] http://www.ubos.org/onlinefiles/ uploads/ubos/pdf documents/UNHS_VI_2017_Version_I_ 27th_September_ 2017.pdf.

7. Ministry of Health U. Health Sector Development Plan 2015/16-2019/20 2015. [Accessed April 28 2019] http://health.go.ug/content/health-sectordevelopment-plan-201516-201920

8. Ministry of Finance Planning and Economic Development. Millennium Development Goals Report for Uganda 2013. Vol 1.; 2015. [Accessed April 28 2019] http://www.undp.org/content/dam/uganda/docs/UNDPUg-2013 MDGProgress Report-Oct 2013.pdf.

9. Ministry of Health Uganda. Annual Pharmaceutical Sector Performance Report 2015-2016.; 2017. [Accessed April 28 2019] http://health.go.ug/content/annual-pharmaceutical-sectorperformance-report-2015-2016-0.

10. Ministry of Health. Annual Pharmaceutical Sector Performace Report 2014/ 15. 2015;(June). [Accessed April 28 2019] http://health.go.ug/content/ annual-pharmaceutical-sector-performance-report

11. Kwesiga B, Wagner A, Seru M, Trap B. Equitable Access to High-Cost Pharmaceuticals Capter 8: Improving Access to High-Cost Medicines in Low Income Countries in Africa: Creating a Functioning Pharmaceutical System In Uganda. (Zaheer-Ud-Din B, ed.). Academic Press Elsevier; 125 London Wall, London EC2Y 5AS, United Kingdom; 2018.

12. Trap B, Ladwar DO, Oteba MO, Embrey M, Khalid M, Wagner AK. Article 1: supervision, performance assessment, and recognition strategy (SPARS) - a multipronged intervention strategy for strengthening medicines management in Uganda: method presentation and facility performance at baseline. J Pharm Policy Pract. 2016;9(1):1-15. https://doi.org/10.1186/ s40545-016-0070-x.

13. Ministry of Health, Pharmacy Department U. National Performance Report on Medicines Management April-June 2015 [Accessed April 28 2019] https://www.health.go.ug/download/file/fid/547

14. Trap B, Musoke R, Kirunda A, Oteba MO, Embrey M, Ross-Degnan D. Article 2: Longitudinal study assessing the one-year effects of supervision performance assessment and recognition strategy (SPARS) to improve medicines management in Uganda health facilities. J Pharm Policy Pract. 2018:11(1). https://doi.org/10.1186/s40545-018-0142-1.

15. Suraratdecha C, Ramana CV, Kaipilyawar S, et al. Cost and effectiveness analysis of immunization service delivery support in Andhra Pradesh. India Bull World Health Organ. 2008;86(3):221-8. https://doi.org/10.2471/ BLT.06.039495.

16. Leech AA, Kim DD, Cohen JT, Neumann PJ. Use and misuse of costeffectiveness analysis thresholds in low- and middle-income countries: trends in cost-per-DALY studies. Value Heal. 2018:1-3. https://doi.org/10. 1016/j.jval.2017.12.016

17. Management Sciences for Health. MDS-3: Managing Access to Medicines and Health Technologies.; 2012. [Accessed April 28 2019] http://apps.who.int/ medicinedocs/documents/s19577en/s19577en.pdf

18. Chukwu OA, Ezeanochikwa VN, Eya BE. Supply chain management of health commodities for reducing global disease burden. Res Soc Adm Pharm. 2017;13(4):871-874. https://doi.org/10.1016/j.sapharm.2016.08.008Get rights and content.

19. Seidman G, Atun R. Do changes to supply chains and procurement processes yield cost savings and improve availability of pharmaceuticals, vaccines or health products? A systematic review of evidence from lowincome and middle-income countries. BMJ Glob Heal. 2017;2(e000243):1-14. https://doi.org/10.1136/bmjgh-2016-000243. 
20. Ministry of Health Uganda. Policy Options Analysis for Uganda's

Pharmaceutical Supply System.; 2010. [Accessed April 28 2019] https://pdf. usaid.gov/pdf_docs/PA00JTFG.pdf

21. Oteba M, Wagner AK, Seru M, Embrey M, Trap B. Pharmaceutical system strengthening in Uganda: implementing a holistic, evidence-informed, longterm strategy. J Pharm Policy Pract. 2018;1 1(1):23. https://doi.org/10.1186/ s40545-018-0150-1.

\section{Publisher's Note}

Springer Nature remains neutral with regard to jurisdictional claims in published maps and institutional affiliations.

Ready to submit your research? Choose BMC and benefit from:

- fast, convenient online submission

- thorough peer review by experienced researchers in your field

- rapid publication on acceptance

- support for research data, including large and complex data types

- gold Open Access which fosters wider collaboration and increased citations

- maximum visibility for your research: over $100 \mathrm{M}$ website views per year

At $\mathrm{BMC}$, research is always in progress. 